\title{
Logische geometrie en pragmatiek
}

\author{
Lorenz Demey en Hans Smessaert
}

Deze bijdrage is een verkenning van de verbanden tussen de logische geometrie en de pragmatiek. Op het vlak van de pragmatiek focussen we op de theorie van implicaturen, meer bepaald scalaire implicaturen. Deze notie is gebaseerd op logische implicaties tussen proposities, en de verschillen in informativiteitsgehalte die hieruit voortvloeien. De logische geometrie is de systematische studie van het klassieke Aristotelische vierkant en zijn uitbreidingen. Deze Aristotelische diagrammen visualiseren de zgn. Aristotelische relaties tussen een gegeven aantal proposities. In de literatuur zijn er twee verschillende definities van de Aristotelische relaties. We tonen aan dat beide definities gerelateerd zijn aan elkaar via de notie van scalaire implicatuur.

\section{Inleiding}

Het Aristotelische vierkant is een veelgebruikt diagram binnen de filosofische logica (andere veelgebruikte termen zijn 'logisch vierkant', 'square of opposition', etc.). Het visualiseert vier formules uit een gegeven logisch systeem, en eveneens een aantal logische relaties tussen deze formules. Deze relaties zijn contradictie, contrariëteit, subcontrariëteit en subalternatie (precieze definities volgen later). Ter illustratie geeft Figuur 1 een Aristotelisch vierkant weer voor de modale logica.

Het vierkant wordt echter niet alleen gebruikt binnen de logica, maar ook binnen de taalkunde, meer bepaald de semantiek en de pragmatiek. Zo vinden we verschillende vierkanten terug in de literatuur over scalaire implicaturen (van der Auwera 1996; Van Belle 2003; Horn 1989, 2004). Het vierkant in Figuur 1, bijvoorbeeld, bevat de subalternatie van 'noodzakelijk $p$ ' naar 'mogelijk $p$ '; hieruit volgt dat 'mogelijk $p$ ' de implicatuur 'niet noodzakelijk $p$ ' genereert (opnieuw: details volgen later).

In de linguïstische literatuur wordt het Aristotelisch vierkant dus gebruikt om de pragmatische notie van scalaire implicatuur te verduidelijken en te illustreren. In deze bijdrage zullen we exact het omgekeerde doen: we zullen namelijk aantonen hoe scalaire implicaturen gebruikt kunnen worden om een zekere ambiguïteit in verband met het Aristotelische vierkant op te helderen. Deze ambiguïteit heeft betrekking op de exacte definitie van de Aristotelische relaties, en kan teruggevonden worden bij auteurs als Horn, die bijvoorbeeld de contrariëteitsrelatie als volgt definieert: "Contraries [are formulas that] cannot be simultaneously true (though they may be simultaneously false)" (Horn 2004, p. 11). De ambiguiiteit betreft de conditie die door Horn tussen haakjes geplaatst wordt: maakt deze conditie integraal deel uit van de

Figuur 1: Aristotelisch vierkant voor de modale logica.

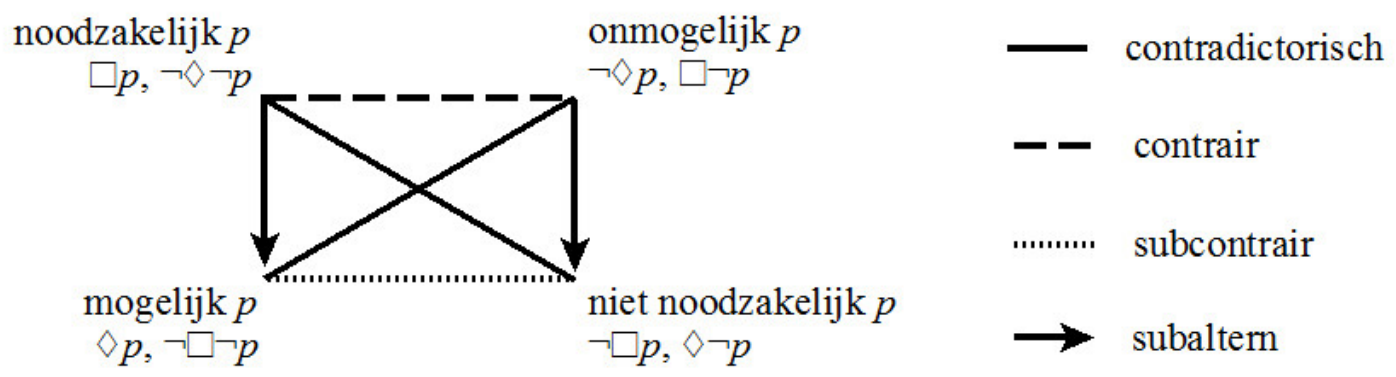


definitie, of kan ze ook achterwege gelaten worden? We zullen aantonen dat beide opties mogelijk zijn, en dat de relatie tussen de twee resulterende definities begrepen kan worden in termen van scalaire implicaturen.

De rest van onze bijdrage is opgebouwd uit vier secties. Sectie 2 is een beknopte inleiding tot de pragmatiek en de notie van scalaire implicatuur. In Sectie 3 schetsen we de bredere theoretische context van het Aristotelische vierkant, nl. de logische geometrie, en formuleren we de twee definities van de Aristotelische relaties. Sectie 4 bevat de kernresultaten van deze bijdrage: we tonen aan dat de twee definities van de Aristotelische relaties gezien kunnen worden als semantisch-pragmatische varianten van elkaar. In Sectie 5 besluiten we deze bijdrage met enkele opmerkingen over het belang van deze resultaten binnen het bredere kader van de logische geometrie.

\section{Scalaire implicaturen}

Eén van de grondleggers van de hedendaagse taalkundige pragmatiek was Grice (1975). Op basis van het coöperatiebeginsel van redelijke conversatie onderscheidt Grice vier maximes: kwantiteit, kwaliteit, relatie en wijze. Deze maximes laten de toehoorder toe om niet-deductieve gevolgtrekkingen, oftewel implicaturen, af te leiden uit de betekenis van de uiting van de spreker. Stel bijvoorbeeld dat een spreker zegt: "Jan stond op en de vaas viel om". De semantische inhoud van deze uitspraak is dat er zich twee feiten hebben voorgedaan: het opstaan van Jan en het omvallen van de vaas. In veel gevallen heeft deze uitspraak, krachtens het maxime van wijze, ook de implicatuur dat er een causaal verband is tussen deze twee feiten. De totale betekenis van deze uitspraak bestaat uit haar semantische inhoud samen met haar implicatuur: het eerste feit heeft zich voorgedaan, en dit heeft ertoe geleid dat ook het tweede feit zich heeft voorgedaan. In deze context noemen we "Jan stond op en daardoor viel de vaas om" de pragmatische vervollediging van "Jan stond op en de vaas viel om". Aangezien implicaturen geen logisch dwingende gevolgtrekkingen zijn, kan de spreker ze te allen tijde nog annuleren of opschorten zonder zichzelf tegen te spreken, door bijvoorbeeld verder te gaan als volgt: "Jan stond op en de vaas viel om... maar dat was niet Jans fout, het was puur toeval".

In deze bijdrage zullen we focussen op het maxime van kwantiteit, dat stelt dat een spreker zo informatief moet zijn als nodig is in de conversatie. Dit maxime werd systematisch bestudeerd door Horn (1989), aan de hand van zgn. Hornschalen. Zo'n schaal heeft de volgende vorm: $<A_{1}, A_{2}, \ldots, A_{n}>$, waarbij er stapsgewijze deductieflogische gevolgtrekkingen zijn van links naar rechts (van $A_{1}$ naar $A_{2}$, van $A_{2}$ naar $A_{3}$, etc.). Aangezien logisch gevolg correleert met informativiteit, is er dus een dalende mate van informativiteit overheen de Hornschaal: $A_{1}$ is het meest informatieve element, en $A_{n}$ het minst informatieve.

Beschouw bijvoorbeeld de positieve schaal die gevormd wordt door de elementen aan de linkerkant van het vierkant in Figuur 1: < noodzakelijk, mogelijk >, en stel dat de spreker zegt: "het is mogelijk dat Marie gelijk heeft". Doordat de minder informatieve notie van mogelijkheid wordt gebruikt, genereert het maxime van kwantiteit de implicatuur dat de meer informatieve notie van noodzakelijkheid niet van toepassing is. Deze scalaire implicatuur is dus: "het is niet noodzakelijk dat Marie gelijk heeft". Als we de semantische inhoud van de uitspraak en haar implicatuur samen nemen, dan bekomen we haar pragmatische vervollediging: "het is mogelijk, maar niet noodzakelijk, dat Marie gelijk heeft". Deze notie ("mogelijk maar niet noodzakelijk') wordt meestal 'contingentie' genoemd in de filosofische logica. 
Beschouw nu de negatieve schaal die gevormd wordt door de elementen aan de rechterkant van het vierkant in Figuur 1: < onmogelijk, niet noodzakelijk >. Volgens exact hetzelfde mechanisme is er een scalaire implicatuur van het minder informatieve element ('niet noodzakelijk') naar de negatie van het meer informatieve element ('niet onmogelijk'). De pragmatische vervollediging van 'niet noodzakelijk' is dan ook 'niet noodzakelijk maar niet onmogelijk', wat opnieuw equivalent is aan contingentie. Deze observatie heeft aanleiding gegeven tot alternatieven en uitbreidingen van het Aristotelische vierkant, zoals driehoeken en hexagons.

Net zoals andere implicaturen, zijn scalaire implicaturen niet logisch dwingend, en kunnen ze dus steeds geannuleerd worden door de spreker. In de volgende twee passages gebruikt de spreker eerst het element 'mogelijk' (resp. 'niet noodzakelijk'), wat de implicatuur 'niet noodzakelijk' (resp. 'niet onmogelijk') genereert; vervolgens wordt deze implicatuur geannuleerd:

"Het is mogelijk dat een vrijgezel niet gehuwd is... eigenlijk is het zelfs noodzakelijk."

"Het is niet noodzakelijk dat een vrijgezel gehuwd is... eigenlijk is het zelfs onmogelijk."

\section{Logische geometrie en de Aristotelische relaties}

Sinds het ontstaan van de formele logica in de geschriften van Aristoteles hebben filosofische logici en (proto)taalkundigen gebruik gemaakt van het Aristotelische vierkant om hun theorieën over logische en linguïstische fenomenen te illustreren. Enkele bekende voorbeelden zijn Avicenna, Johannes Buridanus en William van Sherwood. Gaandeweg werd het vierkant ook uitgebreid naar grotere Aristotelische diagrammen, die meer dan vier formules bevatten, zoals hexagons, octagons, en zelfs driedimensionale polyhedra zoals kubussen en rhombische dodecahedra. In de hedendaagse logica fungeren deze Aristotelische diagrammen vooral als een lingua franca, waarin zowel de overeenkomsten als de verschillen tussen uiteenlopende (modale, epistemische, dynamische, etc.) logische systemen uitgedrukt kunnen worden. We verwijzen naar Smessaert en Demey (2014) voor meer details, voorbeelden en bibliografische referenties.

De logische geometrie is het bredere theoretische kader waarin al deze Aristotelische diagrammen systematisch bestudeerd worden (zie ook de webpagina www.logicalgeometry.org). Typische onderzoeksvragen betreffen de onderlinge samenhang van de Aristotelische diagrammen, en hun logische en visueel-cognitieve eigenschappen. Vanuit een dergelijk systematiserend perspectief blijkt bovendien al snel dat er doorheen de literatuur twee subtiel van elkaar verschillende definities van de Aristotelische relaties gehanteerd worden. Om ze duidelijk van elkaar te kunnen onderscheiden, zullen we hen de 'strikte' en de 'zwakke' definitie noemen.

De strikte definitie komt het vaakst voor in de literatuur; zie bijvoorbeeld Van Belle (2003), Smessaert (2009), Parsons (2010), Smessaert en Demey (2014), en verschillende bijdragen in Béziau en Jacquette (2012). Deze auteurs definiëren de Aristotelische relaties als volgt (het ' $S$ '-prefix geeft aan dat het om de strikte definitie gaat):

1) $\varphi$ en $\psi$ zijn $S$-contradictorisch:

$\varphi$ en $\psi$ kunnen niet samen waar zijn en $\varphi$ en $\psi$ kunnen niet samen vals zijn,

2) $\varphi$ en $\psi$ zijn $S$-contrair: $\varphi$ en $\psi$ kunnen niet samen waar zijn en $\varphi$ en $\psi$ kunnen wel samen vals zijn, 
3) $\varphi$ en $\psi$ zijn $S$-subcontrair:

$\varphi$ en $\psi$ kunnen wel samen waar zijn en $\varphi$ en $\psi$ kunnen niet samen vals zijn,

4) $\varphi$ en $\psi$ zijn $S$-subaltern: als $\varphi$ waar is dan moet ook $\psi$ waar zijn en $\psi$ kan waar zijn terwijl $\varphi$ vals is.

De zwakke definitie, daarentegen, wordt gehanteerd door auteurs zoals Bochenski (1959), McCall (1967) en Seuren (2010). Zij definiëren de Aristotelische relaties als volgt (het ' $Z$ '-prefix geeft aan dat het om de zwakke definitie gaat):

1) $\varphi$ en $\psi$ zijn Z-contradictorisch:

$\varphi$ en $\psi$ kunnen niet samen waar zijn en $\varphi$ en $\psi$ kunnen niet samen vals zijn,

2) $\varphi$ en $\psi$ zijn Z-contrair:

3) $\varphi$ en $\psi$ zijn $Z$-subcontrair:

4) $\varphi$ en $\psi$ zijn Z-subaltern: $\varphi$ en $\psi$ kunnen niet samen waar zijn, $\varphi$ en $\psi$ kunnen niet samen vals zijn, als $\varphi$ waar is dan moet ook $\psi$ waar zijn.

Een eerste blik op deze definities leert ons meteen dat er geen enkel verschil is tussen de strikte en de zwakke notie van contradictie. Daarom zullen we het in de rest van deze bijdrage simpelweg hebben over 'contradictie', zonder S- of Z-prefix. Een meer gedetailleerde vergelijking van de sterke en zwakke definities zal gemaakt worden in de volgende sectie.

\section{Scalaire implicaturen in de Aristotelische relaties}

In de strikte definitie van de Aristotelische relaties kunnen we twee soorten condities onderscheiden. Enerzijds zijn er de tautologiecondities, die stellen dat bepaalde situaties het geval moeten zijn (of: niet het geval kunnen zijn). Anderzijds zijn er de consistentiecondities, die stellen dat bepaalde situaties het geval kunnen zijn. De drie tautologiecondities zijn ' $\varphi$ en $\psi$ kunnen niet samen waar zijn', ' $\varphi$ en $\psi$ kunnen niet samen vals zijn' en 'als $\varphi$ waar is dan moet ook $\psi$ waar zijn'. De drie consistentiecondities zijn ' $\varphi$ en $\psi$ kunnen wel samen waar zijn', ' $\varphi$ en $\psi$ kunnen wel samen vals zijn' en ' $\psi$ kan waar zijn terwijl $\varphi$ vals is'. Als we nu de twee definities van de Aristotelische relaties met elkaar vergelijken, met dit onderscheid in het achterhoofd, dan blijkt dat de zwakke definitie de tautologiecondities overneemt van de sterke definitie, maar de consistentiecondities achterwege laat.

Omdat de strikte definitie zowel de tautologie- als de consistentiecondities gebruikt, is er geen enkele overlap tussen de S-versies van de Aristotelische relaties: als $\varphi$ en $\psi$ in één van de vier (strikte) Aristotelische relaties staan tot elkaar, dan staan ze in geen enkele andere (strikte) Aristotelische relatie tot elkaar. (Tenminste, wanneer $\varphi$ en $\psi$ contingent zijn; zie Lemma 3.2 in Demey 2012 voor details.) In de zwakke definitie, daarentegen, zijn er wél overlappingen tussen de Aristotelische relaties. Het volgt bijvoorbeeld onmiddellijk uit de definities van (Z-)contradictie en Z-contrariëteit dat als twee formules contradictorisch zijn aan elkaar, ze automatisch ook Z-contrair zijn aan elkaar. Met andere woorden, er is een logische implicatie van contradictie naar Z-contrariëteit. Dit logisch feit komt overeen met een informationeel feit: contradictie is informatiever dan Z-contrariëteit. Vanuit pragmatisch perspectief krijgen we daarom de volgende Hornschaal: 
Stel nu dat iemand zegt dat de formules $\varphi$ en $\psi$ Z-contrair zijn aan elkaar. Volgens de zopas gegeven Hornschaal genereert deze uitspraak de scalaire implicatuur dat $\varphi$ en $\psi$ niet contradictorisch zijn aan elkaar. Als we nu de semantische inhoud van de uitspraak samen nemen met haar implicatuur, dan verkrijgen we de volgende conjunctie als totale betekenis:

$\varphi$ en $\psi$ zijn Z-contrair en $\varphi$ en $\psi$ zijn niet contradictorisch

We vervangen nu de noties van Z-contrair en contradictie door hun definities:

( $\varphi$ en $\psi$ kunnen niet samen waar zijn) en

niet: [ ( $\varphi$ en $\psi$ kunnen niet samen waar zijn) en ( $\varphi$ en $\psi$ kunnen niet samen vals zijn) ]

Het tweede conjunct heeft zelf een interne structuur: het is van de vorm 'niet: [A en B]'. Volgens de wetten van De Morgan mag dit herschreven worden als '[niet-A of niet-B]'. Door deze wetten toe te passen, bekomen we dus het volgende:

( $\varphi$ en $\psi$ kunnen niet samen waar zijn) en

[ ( $\varphi$ en $\psi$ kunnen wel samen waar zijn) of ( $\varphi$ en $\psi$ kunnen wel samen vals zijn) ]

Herinner dat men in de Booleaanse logica conjunctie mag distribueren overheen disjunctie: 'A en [B of C]' is equivalent aan '[A en B] of [A en C]'. Door dit principe toe te passen op de bovenstaande conjunctie, bekomen we nu:

[( $\varphi$ en $\psi$ kunnen niet samen waar zijn) en ( $\varphi$ en $\psi$ kunnen wel samen waar zijn)] of [( $\varphi$ en $\psi$ kunnen niet samen waar zijn) en ( $\varphi$ en $\psi$ kunnen wel samen vals zijn)]

Het eerste disjunct is in tegenspraak met zichzelf, omwille van puur logische redenen: het is van de vorm 'A en niet-A'. Als zo'n intern inconsistente zin voorkomt in een disjunctie, dan kunnen we deze zonder probleem weglaten: '(A en niet-A) of $B$ ' is immers equivalent aan ' $\mathrm{B}$ '. Toegepast op de bovenstaande disjunctie betekent dit dat we slechts het tweede disjunct overhouden:

$\varphi$ en $\psi$ kunnen niet samen waar zijn en $\quad \varphi$ en $\psi$ kunnen wel samen vals zijn

Maar dit is exact de definitie van S-contrariëteit! Met andere woorden, als iemand zegt dat de formules $\varphi$ en $\psi$ Z-contrair zijn aan elkaar, dan genereert deze uitspraak een scalaire implicatuur, waardoor de totale betekenis van de uitspraak is dat $\varphi$ en $\psi$ S-contrair zijn aan elkaar. Kernachtig geformuleerd:

\section{S-contrariëteit is de pragmatische vervollediging van Z-contrariëteit.}

We bekijken dit alles nu nog eens vanuit het onderscheid tussen tautologie- en consistentiecondities. Ter herinnering: de definitie van S-contrariëteit maakt gebruik van zowel een tautologieconditie (' $\varphi$ en $\psi$ kunnen niet samen waar zijn') als een consistentieconditie (' $\varphi$ en $\psi$ kunnen wel samen vals zijn'); de definitie van Zcontrariëteit neemt de tautologieconditie over, maar laat de consistentieconditie achterwege. We hebben zonet echter gezien dat de pragmatische vervollediging van 
Z-contrariëteit wel degelijk de consistentieconditie bevat. Daarom kan gesteld worden dat zowel de strikte als de zwakke notie van contrariëteit deze consistentieconditie bevatten: ze zit in de semantiek van S-contrariëteit, en in de pragmatiek van Zcontrariëteit.

Het grote verschil is natuurlijk dat pragmatische implicaturen annuleerbaar zijn, maar semantische aspecten niet. Vergelijk de volgende twee uitspraken:

" $\varphi$ en $\psi$ zijn S-contrair... eigenlijk zijn ze zelfs contradictorisch."

" $\varphi$ en $\psi$ zijn Z-contrair... eigenlijk zijn ze zelfs contradictorisch."

De eerste uitspraak is in tegenspraak met zichzelf, omwille van puur semantischlogische redenen: het volgt onmiddellijk uit de definities van S-contrariëteit en contradictie dat twee formules niet tegelijkertijd S-contrair en contradictorisch kunnen zijn. De tweede uitspraak, daarentegen, is perfect aanvaardbaar: het eerste deel zegt dat $\varphi$ en $\psi$ Z-contrair zijn, waardoor de scalaire implicatuur gegenereerd wordt dat deze formules niet contradictorisch zijn; in het tweede deel wordt deze implicatuur vervolgens geannuleerd.

De argumentatie die we hierboven opgebouwd hebben voor de contrariëteitsrelatie, kan probleemloos getransponeerd worden naar de subcontrariëteitsrelatie. Het vertrekpunt van deze argumentatie was immers de logische implicatie van contradictie naar Z-contrariëteit. Welnu, het is makkelijk verifieerbaar dat er eveneens een logische implicatie is van contradictie naar Z-subcontrariëteit (als twee formules contradictorisch zijn aan elkaar, dan zijn ze automatisch ook Z-subcontrair aan elkaar). Daarom krijgen we ook de volgende Hornschaal:

< contradictie, Z-subcontrariëteit >

Volgens deze Hornschaal zal de uitspraak dat $\varphi$ en $\psi$ Z-subcontrair zijn aan elkaar de scalaire implicatuur genereren dat $\varphi$ en $\psi$ niet contradictorisch zijn aan elkaar. Op exact dezelfde wijze als voorheen vinden we dus ook:

\section{S-subcontrariëteit is de pragmatische vervollediging van Z-subcontrariëteit.}

Tot slot bekijken we subalternatie. Aangezien er geen logische implicatie is van contradictie naar Z-subalternatie, kan de argumentatie die we reeds hebben toegepast op contrariëteit en subcontrariëteit niet blindelings een derde keer herhaald worden. Beschouw echter de relatie van logische equivalentie, die als volgt gedefinieerd is:

$\varphi$ en $\psi$ zijn logisch equivalent: $\quad$ als $\varphi$ waar is dan moet ook $\psi$ waar zijn en als $\psi$ waar is dan moet ook $\varphi$ waar zijn.

Logische equivalentie behoort niet tot het klassieke Aristotelische perspectief, maar is nauw gerelateerd aan contradictie. Zo is logische equivalentie gedefinieerd in termen van twee tautologiecondities, net zoals contradictie (en in tegenstelling tot de drie andere Aristotelische relaties, die gedefinieerd zijn in termen van één tautologieconditie en één consistentieconditie). Omwille van deze reden is het ook zinloos om een onderscheid te maken tussen een $\mathrm{S}$ - en een $\mathrm{Z}$-versie van logische equivalentie. Meer details over de connectie tussen logische equivalentie en de Aristotelische relaties kunnen gevonden worden in Smessaert en Demey (2014). 
Het volgt onmiddellijk uit de definities van logische equivalentie en Zsubalternatie dat als twee formules logisch equivalent zijn aan elkaar, er automatisch ook een Z-subalternatie loopt van de eerste formule naar de tweede. Met andere woorden, er is een logische implicatie van contradictie naar Z-subalternatie, en we bekomen de volgende Hornschaal:

$$
<\text { logische equivalentie, Z-subalternatie }>
$$

Stel nu dat iemand zegt dat de formules $\varphi$ en $\psi$ Z-subaltern zijn. Volgens de zopas gegeven Hornschaal genereert deze uitspraak de scalaire implicatuur dat $\varphi$ en $\psi$ niet logisch equivalent zijn. De totale betekenis (semantische inhoud samen met implicatuur) wordt dus:

$\varphi$ en $\psi$ zijn Z-subaltern en $\varphi$ en $\psi$ zijn niet logisch equivalent

We vervangen de noties van Z-subaltern en logisch equivalent door hun definities:

(als $\varphi$ waar is dan moet ook $\psi$ waar zijn) en

niet: [(als $\varphi$ waar is dan moet ook $\psi$ waar zijn) en (als $\psi$ waar is dan moet ook $\varphi$ waar zijn)]

Net als voorheen kunnen we nu een aantal Booleaanse redeneerstappen toepassen op deze conjunctie, waardoor zij equivalent zal blijken te zijn aan het volgende:

als $\varphi$ waar is dan moet ook $\psi$ waar zijn en $\psi$ kan waar zijn terwijl $\varphi$ vals is

We hebben hiermee ons doel bereikt, want dit is exact de definitie van Ssubalternatie. Als iemand zegt dat de formules $\varphi$ en $\psi$ Z-subaltern zijn, dan genereert deze uitspraak een scalaire implicatuur, waardoor de totale betekenis van de uitspraak is dat $\varphi$ en $\psi$ S-subaltern zijn. Ons derde en laatste resultaat is dan ook:

\section{S-subalternatie is de pragmatische vervollediging van Z-subalternatie.}

Dit resultaat geeft bovendien aanleiding tot dezelfde semantische/pragmatische effecten als in het geval van (sub)contrariëteit. Vergelijk de volgende twee uitspraken:

" $\varphi$ en $\psi$ zijn S-subaltern... eigenlijk zijn ze zelfs logisch equivalent."

" $\varphi$ en $\psi$ zijn Z-subaltern... eigenlijk zijn ze zelfs logisch equivalent."

De eerste uitspraak is in tegenspraak met zichzelf, omwille van puur semantischlogische redenen: het volgt onmiddellijk uit de definities van S-subalternatie en logische equivalentie dat twee formules niet tegelijkertijd S-subaltern en logisch equivalent kunnen zijn. De tweede uitspraak, daarentegen, is perfect aanvaardbaar: het eerste deel zegt dat $\varphi$ en $\psi$ Z-subaltern zijn, waardoor de scalaire implicatuur gegenereerd wordt dat deze formules niet logisch equivalent zijn; in het tweede deel wordt deze implicatuur vervolgens geannuleerd. 


\section{Conclusie}

We hebben in deze bijdrage de verhouding onderzocht tussen de strikte en zwakke definities van de Aristotelische relaties. Voor contradictie is er geen verschil tussen beide definities; voor de drie andere Aristotelische relaties (contrariëteit, subcontrariëteit en subalternatie) hebben we aangetoond dat de strikte versie gezien kan worden als de pragmatische vervollediging van de zwakke versie.

Deze observaties passen op natuurlijke wijze binnen het bredere theoretische kader van de logische geometrie. Het vertrekpunt van onze argumentatie was bijvoorbeeld dat er een logische implicatie is van contradictie naar Z-contrariëteit, waardoor contradictie informatiever blijkt te zijn dan Z-contrariëteit. Aangezien er geen logische implicatie is van contradictie naar S-contrariëteit, lijken we dit informationele perspectief te verliezen binnen de strikte definitie. In Smessaert en Demey (2014) presenteren we echter een gedetailleerde en goed gemotiveerde theorie van de informativiteit van de Aristotelische relaties binnen de strikte definitie. Deze theorie verklaart bijvoorbeeld waarom contradictie wel degelijk informatiever is dan S-contrariëteit, hoewel er geen logische implicatie gaat van de eerste naar de tweede relatie. Deze intuïtieve informativiteitsoordelen worden bovendien bevestigd door een aantal recente, meer technische resultaten binnen de combinatoriek en de algebra.

\section{Referenties}

van der Auwera, Johan. 1996. Modality: The three-layered scalar square. Journal of Semantics 13. 181-195.

Béziau, Jean-Yves \& Dale Jacquette (eds.). 2012. Around and beyond the square of opposition. Basel: Springer.

Bochenski, Jozef. 1959. A precis of mathematical logic. Dordrecht: Reidel.

Demey, Lorenz. 2012. Structures of oppositions in Public Announcement Logic. In Béziau, Jean-Yves \& Dale Jacquette (eds.), 313-339.

Grice, H. Paul. 1975. Logic and conversation. In Cole, Peter \& Jerry Morgan (eds.), Syntax and Semantics, Volume 3: Speech acts, 22-40. New York: Academic Press.

Horn, Laurence. 1989. A natural history of negation. Chicago: University of Chicago Press.

Horn, Laurence. 2004. Implicature. In Horn, Laurence \& Gregory Ward (eds.), The handbook of pragmatics, 3-28. Oxford: Blackwell.

McCall, Storrs. 1967. Contrariety. Notre Dame Journal of Formal Logic 8. 121132.

Parsons, Terence. 2012. The traditional square of opposition. In Ed Zalta (ed.), Stanford encyclopedia of philosophy. Stanford: CSLI.

Seuren, Pieter. 2010. The logic of language. Language from within, Volume II. Oxford: Oxford University Press.

Smessaert, Hans. 2009. On the 3D visualisation of logical relations. Logica Universalis 3. 303-332.

Smessaert, Hans \& Lorenz Demey. 2014. Logical geometries and information in the Aristotelian square of oppositions. Te verschijnen in Journal of Logic, Language and Information. 39pp.

Van Belle, William. 2003. Zwijgen is niet altijd toestemmen. De rol van inferenties bij het interpreteren en argumenteren. Leuven/Leusden: Acco. 